\title{
Complementary and Alternative Medicine-related Drug-induced Liver Injury in Iran
}

\author{
Mehdi Pasalar ${ }^{1,2}$, Babak Daneshfard*3 ${ }^{3}$ and Kamran Bagheri Lankarani ${ }^{4}$ \\ ${ }^{1}$ Research Center for Traditional Medicine and History of Medicine, Shiraz University of Medical Sciences, Shiraz, Iran; ${ }^{2}$ Essence of \\ Parsiyan Wisdom Institute, Phytopharmaceutical Technology and Traditional Medicine Incubator, Shiraz University of Medical \\ Sciences, Shiraz, Iran; ${ }^{3}$ Traditional Medicine Clinical Trial Research Center, Shahed University, Tehran, Iran; ${ }^{4}$ Health Policy \\ Research Center, Shiraz University of Medical Sciences, Shiraz, Iran
}

Citation of this article: Pasalar M, Daneshfard B, Lankarani $\mathrm{KB}$. Complementary and alternative medicine-related druginduced liver injury in Iran. J Clin Transl Hepatol 2020;8(1): 106-107. doi: 10.14218/JCTH.2020.00008.

Dear Editor,

We read the interesting review article by Philips et al. ${ }^{1}$ regarding the complementary and alternative medicine (CAM)-related drug-induced liver injury (DILI) in Asian countries. They have addressed a critical issue in CAM practice which has posed a serious challenge to healthcare providers all around the world.

The authors have vigorously reviewed the evidence from India and many East Asian countries, however, they did not comment on the situation in West Asia. Traditional Persian medicine (TPM) is one of the oldest comprehensive schools of medicine, with a history of more than 7000 years which is practiced in the Middle East and India widely today. It is a Hikmat (philosophy)-based holistic medical school based on humoral medicine, including the theory of mizadj (temperament) as well. ${ }^{2}$ Introducing the genius sages, such as Avicenna (980-1037 AD) ${ }^{3}$ and Rhazes (865-925 AD), ${ }^{4}$ TPM has played an important role in the progression of medical sciences across the world.

There is an observed increasing trend of CAM usage in Asian countries, including West Asian countries and in the Middle East, for various acute and chronic ailments. ${ }^{5,6}$ This increase in use of traditional medicines, along with widely accepted belief that herbal therapy is totally harmless, has resulted in increasingly greater occurrence of liver injuries caused by these remedies. For instance, in our center, we have faced few hepatotoxicity cases due to inappropriate consumption of borage (Echium amoenum) resulting in hepatic failure and hospital admission. It is worthy of mention that based on the temperamental viewpoint in TPM, many of the hepatotoxic herbs, such as $E$. amoenum, possess hot and dry nature, which can increase the liver enzymes - even causing liver failure.

Abbreviations: CAM, complementary and alternative medicine; DILI, druginduced liver injury; TPM, traditional Persian medicine.

Received: 29 January 2020; Accepted: 23 March 2020

* Correspondence to: Babak Daneshfard, Traditional Medicine Clinical Trial Research Center, Shahed University, Enghelab Sq., North Kargar St., No. 1471, Tehran 1417953836, Iran. Tel/Fax: +98-21-66464322, E-mail: babakdaneshfard@gmail.com
As mentioned correctly by Philips et al., ${ }^{1}$ one of the major limitations in identifying these side effects is absence of labeling that mentions the ingredient and component details of the remedies. A national survey in Iran revealed that a considerable portion of medicinal plants available in the market are faced with ambiguous identification, contamination, and adulteration. ${ }^{7}$ These problems occur mainly in traditional herbal shops (Attari), which are also the most common source of medicinal herb delivery and often present their products in a disordered and messy set-up (Fig. 1).

In the past decade, Iran has started a new model of promoting evidence-based traditional medicine. Many research centers are working on providing evidence for the effectiveness of these remedies. ${ }^{8}$ Realizing the personal nature of disease in the philosophy of TPM, the target is to find which drug is effective for which patient. Knowing the temperaments of the patients is one of the mainstays in this approach.

The Ministry of Health and Medical Education in Iran has established a specialized office to promote the use of TPM while supervising the practice and products. The main mission is to provide the remedies with good manufacturing practice and under strict control within the industry (Fig. 2).

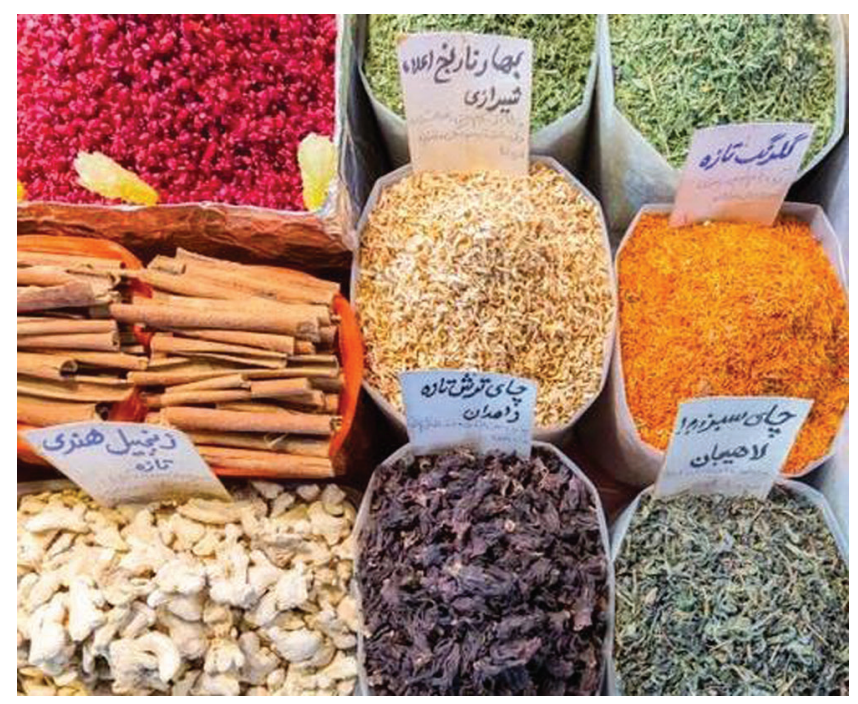

Fig. 1. Medicinal herb delivery in a representative Iranian traditional herbal shop (Attari). 


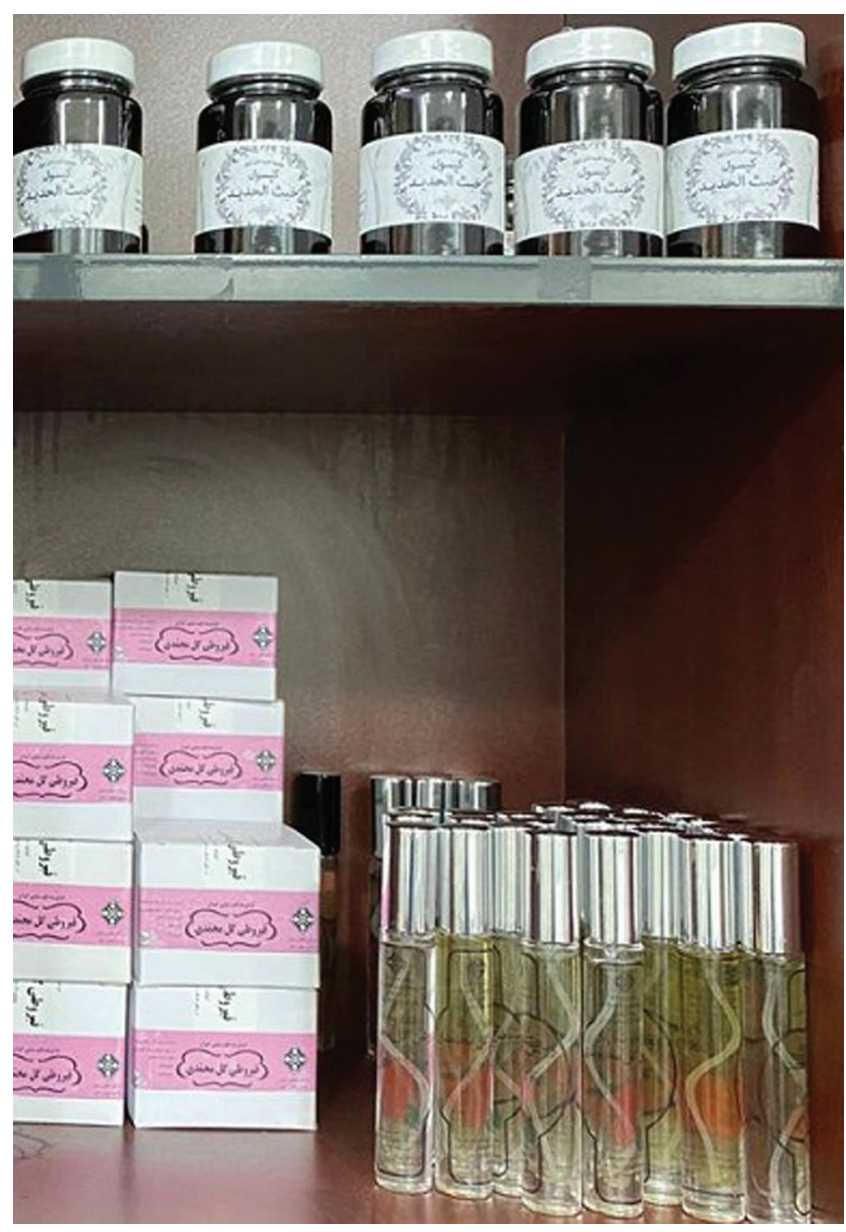

Fig. 2. Herbal medicine delivery in a representative university-affiliated health center in Iran.
New legislation and regulatory processes have been issued by the health authorities in recent years and active supervision is currently running in Iran. Hence, there is still a long way to go until we reach a desirable state in the healthcare delivery of CAM.

\section{Funding}

None to declare.

\section{Conflict of interest}

The authors have no conflict of interests related to this publication.

\section{References}

[1] Philips CA, Augustine P, Rajesh S, Y PK, Madhu D. Complementary and alternative medicine-related drug-induced liver injury in Asia. J Clin Transl Hepatol 2019;7:263-274. doi: 10.14218/JCTH.2019.00024.

[2] Atarzadeh F, Daneshfard B, Dastgheib L, Jaladat AM, Amin G. Early description of diet-induced blistering skin diseases in Medieval Persia: Avicenna's point of view. Skinmed 2016;14:367-370.

[3] Nimrouzi M, Tafazoli V, Daneshfard B, Zare M. Optimal fluid intake in daily diet: Avicenna's view. J Integr Med 2016;14:241-244. doi: 10.1016/S2095-4964 (16)60262-5.

[4] Daneshfard B, Dalfardi B. Medieval roots of modern knowledge regarding carotid sinus syncope. Int J Cardiol 2014;173:342-343. doi: 10.1016/j. ijcard.2014.03.030.

[5] Bordbar M, Pasalar M, Safaei S, Kamfiroozi R, Zareifar S, Zekavat O, et al. Complementary and alternative medicine use in thalassemia patients in Shiraz, southern Iran: A cross-sectional study. J Tradit Complement Med 2017:8:141-146. doi: 10.1016/j.jtcme.2017.05.002

[6] Hashempur MH, Heydari M, Mosavat SH, Heydari ST, Shams M. Complementary and alternative medicine use in Iranian patients with diabetes mellitus. J Integr Med 2015;13:319-325. doi: 10.1016/S2095-4964(15) 60196-0.

[7] Joharchi MR, Amiri MS. Taxonomic evaluation of misidentification of crude herbal drugs marketed in Iran. Avicenna J Phytomed 2012;2:105-112.

[8] Pasalar M, Vardanjani HM. Trend of clinical trials in Persian medicine: a decade of endeavours. Integr Med Res 2020;9:10-11. doi: 10.1016/j.imr.2019.11. 010 . 